\title{
Growth of Haemophilus influenzae type b in the presence of bovine aortal endothelial cells
}

\author{
P. R. LANGFORD* and E. R. MOXON \\ Department of Paediatrics, Level 4, John Radcliffe Hospital, Oxford OX3 9DU, UK
}

(Received 22 November 1990; revised 8 February 1991; accepted 4 March 1991)

\begin{abstract}
In serum-free medium in the presence of bovine aortal endothelial cells (BAOEC), Haemophilus influenzae type b was capable of extensive proliferation compared to that in serum-free medium alone. An unidentified lowmolecular-mass ( $<2000 \mathrm{kDa}$ ) compound(s) was, in part, responsible for this phenomenon. There were changes in the outer-membrane protein profiles between broth-grown (the original inoculum) and BAOEC-grown organisms, particularly in the 45-70 kDa range. Both broth- and BAOEC-grown bacteria were serum sensitive in vitro but could be converted to a serum-resistant phenotype, resembling that found in vivo, by incubation in a serum filtrate.
\end{abstract}

\section{Introduction}

Haemophilus influenzae is one of the commonest causes of bacterial meningitis in the UK and USA, with serotype $b$ strains accounting for $>90 \%$ of all cases (Turk, 1984). However, the mechanism(s) by which the organism passes from the nasopharynx to the blood and subsequently to the cerebrospinal fluid are unknown. The possibility of $H$. influenzae-endothelial cell interactions occurs when the organisms enter the vascular compartment prior to bloodstream dissemination and at the endothelial cell/central nervous system barrier. In a rat model of $H$. influenzae meningitis, increased permeability to albumin and increased pinocytotic activity in cerebral endothelia were observed (Quagliarello et al., 1986). Studies designed to elucidate the identity and role of $H$. influenzae surface components in endothelial cell interactions were initiated. As a model system bovine aortal endothelial cells (BAOEC) were chosen due to their comparative ease of isolation and culture compared to brain endothelial cells. In the presence of serum there was a rapid increase in cell numbers, growth curves being identical, irrespective of the presence of BAOEC. However, in serum-free medium, in the presence of BAOEC, $H$. influenzae was capable of extensive proliferation compared to that in serum-free medium alone. This latter phenomenon was investigated further and it was found that BAOEC secrete as yet unknown compounds

Abbreviations: BAOEC, bovine aortal endothelial cells; OMP, outermembrane protein. into the medium allowing extended growth of $H$. influenzae.

\section{Methods}

Bacterium and growth conditions. H. influenzae type b strain Eagan (Anderson et al., 1972) was used. It was grown to mid-exponential phase in Brain Heart Infusion (BHI) broth supplemented with $2 \mu \mathrm{g}$ NAD ml-1 and $10 \mu \mathrm{g}$ haemin $\mathrm{ml}^{-1}$ at $37^{\circ} \mathrm{C}$ on an orbital incubator (200 r.p.m.). For viable counts, appropriate dilutions were plated onto BHI agar plus Levinthal base and incubated at $37^{\circ} \mathrm{C}$ for $18 \mathrm{~h}$. Before addition to BAOEC, strain Eagan was diluted in pre-warmed $\left(37^{\circ} \mathrm{C}\right)$ MEM (Gibco 041-01090) as indicated in Results.

Isolation and cultivation of BAOEC. Adult BAOEC were prepared by collagenase digestion of isolated vessels (Schwartz, 1978), characterized morphologically and by the presence of factor VIII, and used between the 12th and 25th passage (Harlan et al., 1981). BAOEC were grown to confluence at $37^{\circ} \mathrm{C}$ in $5 \%(v / v)$ carbon dioxide in MEM, $10 \%$ (v/v) foetal bovine serum replacement (Ryan Growth Supplement, Miami, Florida) and $5 \%(\mathrm{v} / \mathrm{v})$ foetal bovine serum (Gibco). For serumfree conditions BAOEC were washed a minimum of six times in MEM and finally replaced in MEM. Growth of BAOEC monolayers for $20 \mathrm{~h}$ in the latter conditions was the source of serum-free BAOEC supernatants. These were centrifuged $(3000 \mathrm{~g}, 10 \mathrm{~min})$ and the supernatants used directly or stored at $-20^{\circ} \mathrm{C}$ until required.

Dialysis experiment. Aliquots $(2 \mathrm{ml})$ of $\mathrm{MEM} \pm$ bacteria $\left(1 \times 10^{4}\right.$ c.f.u. $\left.\mathrm{ml}^{-1}\right)$ were placed in sterile dialysis bags (Sigma, cut-off $2000 \mathrm{kDa}$ ), sealed and aseptically transferred to T25s (C3055, NBL, Northumberland, UK) containing $5 \mathrm{ml} \mathrm{MEM}$ with confluent BAOEC monolayers \pm bacteria. Viable counts of the contents of the dialysis bags and external culture medium were taken after $20 \mathrm{~h}$.

Outer-membrane protein (OMP) profiles. Outer membranes were obtained by Sarkosyl extraction and OMP profiles determined by SDS- 
PAGE as described by Allan et al. (1987). Gels were silver-stained using the Amersham Kit (RPN.17). Protein concentration was measured by the modification of the method of Bradford (1976) as described by Stoscheck (1990), using bovine serum albumin as the standard.

Serum sensitivity. BHI- and BAOEC-grown orgnisms were washed once in ice-cold PBS and used directly or after incubation in PBSB \pm serum filtrate for $30 \mathrm{~min}$ at $0{ }^{\circ} \mathrm{C}$. PBSB is PBS, $0.15 \mathrm{~mm}$ calcium chloride, $0.5 \mathrm{~mm}$-magnesium chloride and $0.1 \%$ bovine serum albumin. Human serum filtrate (Anderson et al., 1980) was provided by Dr M. Virji of this department. The anti-somatic (non-capsular) bactericidal activity of human sera was assessed by incubating approximately $1 \times 10^{4}$ c.f.u. $\mathrm{ml}^{-1}$ of strain Eagan in $25 \%(\mathrm{v} / \mathrm{v})$ (in PBSB) normal or complement-inactivated (heat-treated at $56^{\circ} \mathrm{C}$ for $30 \mathrm{~min}$ ) adult human serum absorbed with $H$. influenzae type b capsule (PRP) in a final volume of $100 \mu \mathrm{l}$. Each $1 \mathrm{ml}$ of serum was absorbed with $30 \mu \mathrm{g}$ PRP (b-CAPSA I Vaccine, Praxis Biologicals, Rochester, New York, USA) for $30 \mathrm{~min}$ at $37^{\circ} \mathrm{C}$ followed by $2 \mathrm{~h}$ at $4{ }^{\circ} \mathrm{C}$, and small aliquots were stored at $-70^{\circ} \mathrm{C}$ until required (Shaw et al., 1976). The percentage of bacteria that remained was determined by comparison of viable counts before and after incubation for $30 \mathrm{~min}$ at $37^{\circ} \mathrm{C}$.

\section{Results and Discussion}

\section{Growth of $H$. influenzae in the presence and absence of $B A O E C$}

The growth of $H$. influenzae at two different inocula in the presence and absence of BAOEC in serum-free media is shown in Fig. 1. In contrast to MEM alone, bacterial cell numbers in MEM + BAOEC rapidly increased from time zero and eventually reached a plateau level. The concentration of bacteria at the plateau level was different with the two inoculum sizes used. The basis for this phenomenon is unknown. When bacteria were grown in BAOEC supernatants viable counts increased, although there was some variation in numbers between batches (Fig. 1). In order to determine if the compound(s) released by BAOEC was of high or low molecular mass, an in situ dialysis experiment was done (Table 1). Bacteria present in infected dialysis bags (IO, I) were capable of growth to approximately two orders of magnitude lower than bacteria in the external medium (IO, O). The concentration of bacteria in the dialysis bag was lower in the experiment where the external medium had also been inoculated (IO) as compared to when bacteria were present only in the dialysis bag (I). Use of the BAOEC-excreted compound(s) by bacteria in the external medium probably limits the amount available for growth in the dialysis bag in this case (IO). The lower level of bacteria in the dialysis bag inoculated alone (I), compared to that found in the external medium $(\mathrm{O})$, may reflect slow diffusion of the compound(s) into the dialysis bag or alternatively that a compound of higher molecular mass may also be

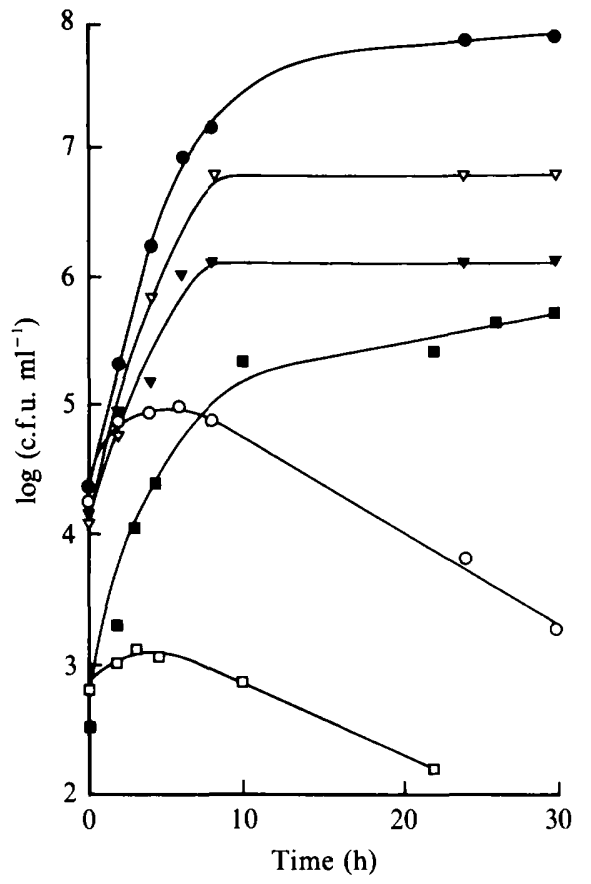

Fig. 1. Growth curves of $H$. influenzae. Starting inoculum of $2 \times 10^{4}$ c.f.u. $\mathrm{ml}^{-1} ; \operatorname{MEM}+\operatorname{BAOEC}(O) ; \operatorname{MEM}$ alone (O); two separate batches of BAOEC supernatants $(\nabla, \nabla)$. Starting inoculum of $2.9 \times 10^{2}$ c.f.u. $\mathrm{ml}^{-1} ;$ MEM + BAOEC ( $\left.\square\right) ;$ MEM alone ( $\square$ ). Results are the means of duplicate samples from duplicate flasks.

involved in the observed phenomenon. This was not pursued further.

The results suggest that $H$. influenzae can use a nutrient(s) derived from BAOEC to sustain growth in the serum-free conditions used in this study. The dialysis experiment indicated that the factor(s) responsible is, at least in part, of low molecular mass $(<2000 \mathrm{kDa})$. In order to try to identify any compounds that may have been responsible for the observed phenomenon, we have screened amino acids, vitamins, nucleotides, nucleosides and miscellaneous other compounds for their ability to prolong the survival of $H$. influenzae in MEM. The only compounds that individually or combined (final concentration in parentheses), resulted in a marginal increase $(<0.5 \mathrm{log})$ in bacterial cell numbers at $20 \mathrm{~h}$ were: (1) NAD $\left(10 \mu \mathrm{g} \mathrm{ml}^{-1}\right)$, (2) haemin $\left(10 \mu \mathrm{g} \mathrm{ml} \mathrm{m}^{-1}\right)$, (3) glutamine $(2 \mathrm{mM})$ and (4) glutathione $\left(30 \mu \mathrm{g} \mathrm{ml}^{-1}\right)$. The observed phenomenon is not restricted to BAOEC. High levels $\left(10^{5}-10^{6}\right.$ c.f.u. $\left.\mathrm{ml}^{-1}\right)$ of $H$. influenzae type b persisted in Eagle's basic medium when grown in the presence of tracheal organ cultures. Histological studies showed that loss of cilia and damage to epithelial cells occurred. A ciliostatic substance, probably lipopolysaccharide (LPS), was released into the growth medium (Denny, 1974). 
Table 1. Dialysis experiment

Aliquots $(2 \mathrm{ml})$ of MEM \pm bacteria $\left(1 \times 10^{4}\right.$ c.f.u. $\left.\mathrm{ml}^{-1}\right)$ were incubated in dialysis bags (cut-off $2000 \mathrm{kDa}$ ) placed in $5 \mathrm{ml}$ MEM with confluent BAOEC monolayers \pm bacteria $\left(1 \times 10^{4}\right.$ c.f.u. $\left.\mathrm{ml}^{-1}\right)$. Bacterial counts in the dialysis bags and the external medium were determined after $20 \mathrm{~h}$, and are shown \pm SEM. The results are the means of duplicate experiments. ND, Below detectable limits.

\begin{tabular}{llllll}
\hline \hline & \multicolumn{2}{c}{ Contents of: } & & \multicolumn{2}{c}{ Bacterial counts in: } \\
\cline { 2 - 3 } \cline { 5 - 6 } & Dialysis bag & External medium & & Dialysis bag & External medium \\
\hline IO & MEM + bacteria & MEM + bacteria & & $9.33 \pm 0.36 \times 10^{4}$ & $1.33 \pm 0.13 \times 10^{7}$ \\
I & MEM + bacteria & MEM alone & & $1.97 \pm 0.24 \times 10^{5}$ & ND \\
O & MEM alone & MEM + bacteria & & ND & $1 \cdot 23 \pm 0.05 \times 10^{7}$ \\
$X$ & MEM alone & MEM alone & & ND & ND \\
\hline \hline
\end{tabular}

Control monolayers (MEM alone) and those incubated with bacteria maintained their integrity as adjudged morphologically after $8 \mathrm{~h}$. At $20 \mathrm{~h}$ there was extensive breakdown of monolayers where bacteria were present; control monolayers were intact (Fig. 2). One possible bacterial substance that could have contributed to detachment and cell death is LPS, an integral component of the Gram-negative cell wall (Lugtenburg \& van Alphen, 1983). The cytotoxic effect of either smooth LPS from Escherichia coli or rough LPS from Salmonella minnesota on BAOEC has been documented (Harlan et al., 1983), BAOEC being less susceptible to $E$. coli LPS when grown under serum-free conditions. $H$. influenzae produces LPS of the rough form (Inzana, 1983). Experiments in this laboratory showed that LPS extracted from strain Eagan was cytotoxic to BAOEC when lactate dehydrogenase release was used as the indicator of cell damage (Langford et al., 1991). In rats, intra-cisternal inoculation of purified $H$. influenzae LPS caused increased blood-brain barrier permeability (Wispelway et al., 1988).

\section{OMP profiles}

Bacteria can alter their metabolism and composition in response to environmental change. The expression of surface components in vivo can be very different to that in vitro (Brown \& Williams, 1985). H. influenzae type b has the ability to survive in many different growth environments, including the nasopharynx, blood, macrophages (Williams et al., 1991) and cerebrospinal fluid. Notwithstanding the many in vivo modes of growth possible, the fact that $H$. influenzae can use a compound(s) for growth from BAOEC suggested that this in vitro environment might mimic that in vivo more closely than BHI. To determine whether a phenotypic change had occurred in surface components, OMP profiles of BAOEC- and BHI-grown bacteria were determined. BAOEC- and
BHI-grown cells were compared since only a few bacteria remained in MEM alone after $20 \mathrm{~h}$ and BHIgrown cells were the original inoculum used.

There were more minor proteins in BAOEC-supernatant-grown bacteria, particularly in the range 45$70 \mathrm{kDa}$ (Fig. 3). Similar results were found with two separate extractions. When BAOEC supernatant alone was used no Sarkosyl-insoluble material was found, although a single $48 \mathrm{kDa}$ protein was found when BAOEC were used as the starting material (data not shown). The changes observed may be due to the different growth media used (BHI vs MEM) or different growth phase (exponential with BHI-grown cells and stationary with MEM-supernatant-grown cells). In both strain Eagan in the same range (P. R. Langford, A. Williams \& E. R. Moxon, unpublished) and in another $H$. influenzae type b strain in the $50-75 \mathrm{kDa}$ range (van Alphen et al., 1990), minor proteins were more abundant in outer membranes isolated from bacteria harvested directly from the peritoneal cavity of infected rats than in those obtained from broth-grown organisms. It was postulated that, in the latter study, some of these additional proteins were iron-regulated. Morton \& Williams (1990) showed that strain Eagan had the same OMP profile, with silver staining, when grown in ironreplete or iron-limited conditions. It is possible, therefore, that the additional proteins found in BAOECgrown strain Eagan are not iron regulated.

\section{Serum sensitivity}

Broth-grown strain Eagan is more susceptible to the complement-mediated bactericidal activity of antisomatic antibodies than are organisms harvested directly from the nasopharynx (Rubin \& Moxon, 1985) or the blood of infected rats (Shaw et al., 1976). Broth-grown serum-sensitive strain Eagan can be converted to the serum-resistant phenotype, resembling that observed in 

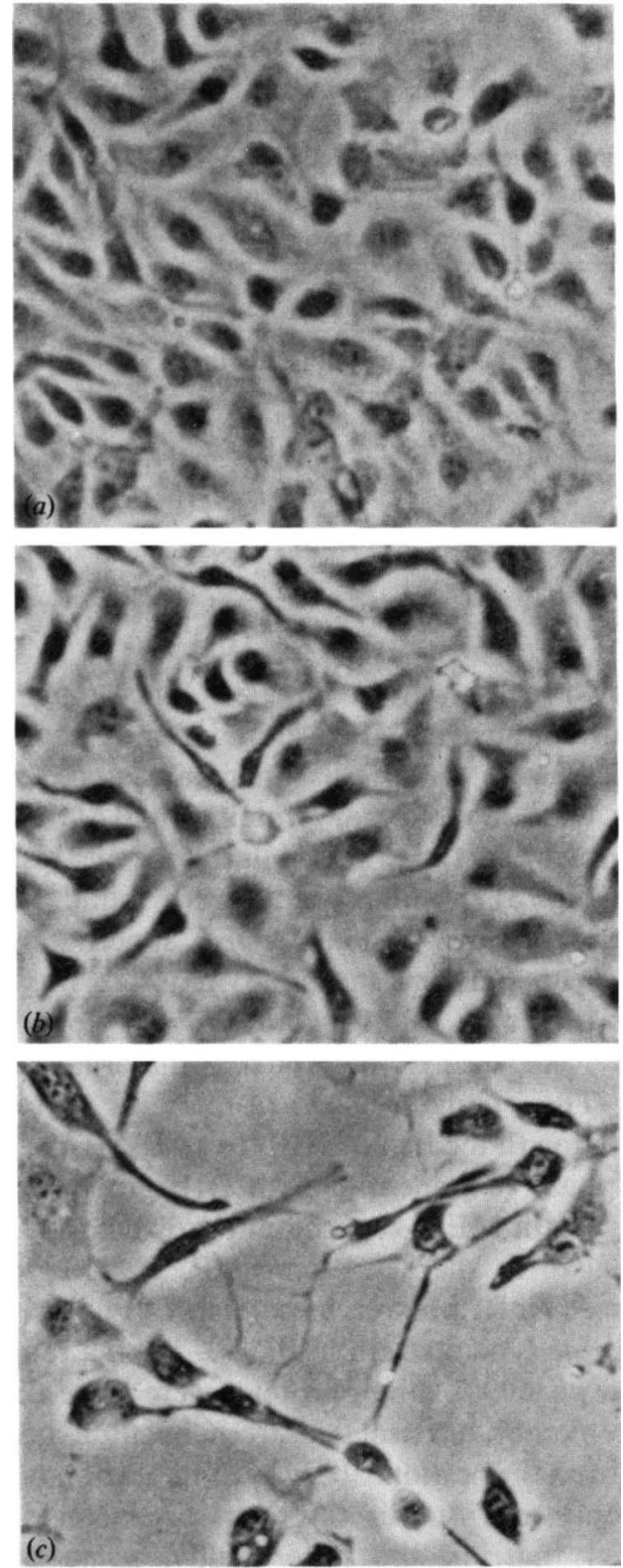

Fig. 2. Phase-contrast photographs of confluent BAOEC monolayers grown for $20 \mathrm{~h}$ in (a) MEM, $10 \%$ foetal bovine serum replacement and $5 \%$ foetal bovine serum; $(b)$ MEM alone; and (c) MEM $+H$. influenzae (starting inoculum $1 \times 10^{4}$ c.f.u. $\mathrm{ml}^{-1}$ ).

vivo, by incubation in filtrates of rat (Shaw et al., 1976) or human (Anderson et al., 1980) sera. The anti-somatic bactericidal activities of human sera against BHI- and BAOEC-grown orgnisms were therefore compared. There was a reproducible statistically significant $(P<0 \cdot 01$, Student's t-test), but not substantial, difference in the mean number of bacteria that remained between samples which had been incubated in normal (PRP-absorbed) serum. Both BHI- and BAOEC-grown

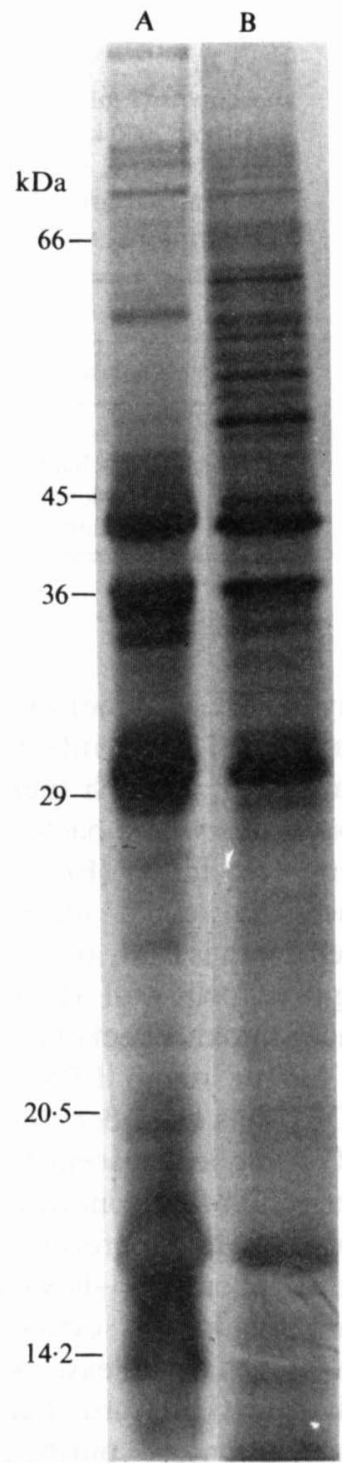

Fig. 3. SDS-PAGE gel $(12.5 \%, \mathrm{w} / \mathrm{v}$, acrylamide; $10 \mu \mathrm{g}$ protein per lane) of (A) BHI-grown and (B) BAOEC-supernatant-grown $H$. influenzae.

organisms were converted to the serum-resistant phenotype after incubation in serum filtrate (Table 2). Use of BHI- or BAOEC-grown organisms directly, rather than pre-incubated in PBSB for $30 \mathrm{~min}$ at $0{ }^{\circ} \mathrm{C}$ prior to the bactericidal assay, made no difference to the results (data not shown). Diminished bactericidal activity was observed for heat-treated (complement-inactivated) sera in all cases. Complement is crucial for the normal clearance of $H$. influenzae from blood (Crosson et al., 1976), the most likely mechanism being $\mathrm{C} 3$ mediating association of organisms with macrophages (Noel et al., 1990).

As knowledge accumulates of the composition and characteristics of in vivo-grown organisms then it should 
Table 2. Sensitivity of strain Eagan to normal and heat-treated (complement-inactivated) adult human sera absorbed with PRP

The percentages of bacteria \pm SEM that remained after incubation of $1 \times 10^{4}$ c.f.u. ml $\mathbf{m}^{-1}$ bacteria in serum for $30 \mathrm{~min}$ at $37^{\circ} \mathrm{C}$ are shown. BHI- and BAOEC-grown bacteria were pre-incubated in PBSB or serum filtrate for $30 \mathrm{~min}$ at $0^{\circ} \mathrm{C}$ prior to the bactericidal assay. The results are the means of triplicate determinations.

\begin{tabular}{lrc}
\hline \multirow{2}{*}{$\begin{array}{c}\text { Growth condition }+ \\
\text { pre-incubation medium }\end{array}$} & \multicolumn{1}{c}{ Human serum (PRP absorbed) } \\
\cline { 2 - 3 } & \multicolumn{1}{c}{ Normal } & Heat treated \\
\hline BHI \pm PBSB & $0.78 \pm 1.08$ & $125.21 \pm 18.95$ \\
BHI + filtrate & $106.58 \pm 8.18$ & $135.00 \pm 8.75$ \\
BAOEC + PBSB & $5.97 \pm 3.25$ & $111.66 \pm 18.37$ \\
BAOEC + filtrate & $100.90 \pm 6.62$ & $96.47 \pm 11.52$ \\
\hline \hline
\end{tabular}

be possible to formulate media and growth conditions in vitro which mimic more closely those found in vivo. Whilst BAOEC-grown organisms did not possess the serum resistance trait associated with in vivo-grown bacteria, it remains to be determined whether the additional OMPs found are present in infection and have a role in pathogenesis.

This work was supported by MRC Programme and Wellcome Trust grants to E. R. M. Thanks are due to Dr A. Hussein for conveying the original observation and for helpful discussions.

\section{References}

Allan, I., Loeb, M. R. \& Moxon, E. R. (1987). Limited genetic diversity of Haemophilus influenzae (type b). Microbial Pathogenesis 2 , 139-145.

van Alphen, L., Geelen-van den Broek, L. \& van Ham, M. (1990). In vivo and in vitro expression of outer membrane components of Haemophilus influenzae. Microbial Pathogenesis 8, 279-288.

ANDERSON, P., Johnston, R. B. \& SMith, D. H. (1972). Human serum activities against Haemophilus influenzae, type b. Journal of Clinical Investigation 51, 31-38.

Anderson, P., Flesher, A., Shaw, S. \& Harding, A. L. (1980). Phenotypic and genetic variation in the susceptibility of Haemophilus influenzae type b to antibodies to somatic antigens. Journal of Clinical Investigation 65, 885-891.

BRADFORD, M. M. (1976). A rapid and sensitive method for the quantitation of microgram quantities of protein using the principle of dye binding. Analytical Biochemistry 72, 248-254.
Brown, M. R. W. \& Williams, P. (1985). The influence of the environment on envelope properties affecting the survival of bacteria in infection. Annual Review of Microbiology 39, 527-556.

Crosson, F. J., Winkelstein, J. A. \& Moxon, E. R. (1976). Participation of complement in the non-immune host defense against experimental Haemophilus influenzae type b septicemia and meningitis. Infection and Immunity 14, 882-887.

DENNY, F. W. (1974). Effect of a toxin produced by Haemophilus influenzae on cultured respiratory epithelium. Journal of Infectious Diseases 129, 93-100.

Harlan, J. M., Killen, P. D., Harker, L. A., Striker, G. E. \& WRIGHT, D. G. (1981). Neutrophil-mediated endothelial injury in vitro: mechanisms of cell detachment. Journal of Clinical Investigation 68, 1394-1403.

Harlan, J. M., Harker, L. A., Reidy, M. A., Gajdusek, C. M., SCHWARTZ, S. M. \& STRIKER, G. E. (1983). Lipopolysaccharidemediated bovine cell injury in vitro. Laboratory Investigation 48, 269274.

INZANA, T. J. (1983). Electrophoretic heterogeneity and interstrain variation of the lipopolysaccharide of Haemophilus influenzae. Journal of Infectious Diseases 148, 492-499.

LANGFord, P. R., Szabo, M. \& MoXon, E. R. (1991). In vitro cytotoxicity of Haemophilus influenzae lipopolysaccharide for bovine aortal endothelial cells. FEMS Microbiology Letters (in the press).

LUGTENBURG, B. \& VAN ALPHEN, L. (1983). Molecular architecture and functioning of the outer membrane of Escherichia coli and other Gram-negative bacteria. Biochimica et Biophysica Acta 737, 51-115.

MORTON, D. J., \& Williams, P. (1990). Siderophore-independent acquisition of transferrin bound iron by Haemophilus influenzae type b. Journal of General Microbiology 136, 927-934.

Noel, G. J., Mosser, D. M. \& Edelson, P. J. (1990). Role of complement in mouse macrophage binding of Haemophilus influenzae type b. Journal of Clinical Investigation 85, 208-218.

Quagliarello, V. T., LoNG, W. J. \& SCheld, W. M. (1986) Morphological alterations of the blood-brain barrier with experimental meningitis in the rat. Temporal sequence and role of encapsulation. Journal of Clinical Investigation 77, 1084-1095.

Rubin, L. G. \& Moxon, E. R. (1985). The effect of serum factor induced resistance to somatic antibodies on the virulence of Haemophilus influenzae type b. Journal of General Microbiology 131, 515-520.

SCHWARTZ, S. M. (1978). Selection and characterization of bovine aortic endothelial cells. In Vitro 14, 966-980.

Shaw, S., Smith, A. L., Anderson, P. \& Smith, D. H. (1976). The paradox of Haemophilus influenzae type b bacteremia in the presence of serum bactericidal activity. Journal of Clinical Investigation 58, 1019-1029.

STOSCHECK, C. M. (1990). Increased uniformity in the response of the coomassie blue $\mathrm{G}$ protein assay to different proteins. Analytical Biochemistry 184, 111-116.

TURK, D. C. (1984). The pathogenicity of Haemophilus influenzae. Journal of Medical Microbiology 18, 1-16.

Williams, A., Maskell, D. \& Moxon, E. R. (1991). Relationship between intracellular survival in macrophages and virulence of Haemophilus influenzae type b. Journal of Infectious Diseases (in the Press).

Wispel way, B., Lesse, A. J., Hansen, E. J. \& Scheld, W. M. (1988). Haemophilus influenzae lipopolysaccharide induced blood-brain barrier permeability during experimental meningitis in the rat. Journal of Clinical Investigation 82, 1339-1346. 